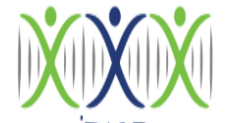

IRASD

Volume 9, Number 3, 2021, Pages 392-398

\title{
Prevalence of Depression, Anxiety, and Stress Among University Students After the COVID-19 First Wave in Pakistan
}

\author{
Wizra Saeed ${ }^{1}$, Saira Irfan², Neelam Zafar ${ }^{3}$, Faiqa Cheema ${ }^{4}$ \\ ${ }^{1}$ Department of Professional Psychology, Bahria University Islamabad, Pakistan, Email: wizrasaeed@gmail.com \\ 2 Department of Applied Psychology, University of Sahiwal, Pakistan Email: sairairfan@uosahiwal.edu.pk \\ ${ }^{3}$ Department of Applied Psychology, University of Sahiwal, Pakistan, Email: neelamzafar@gmail.com \\ ${ }^{4}$ Clinical psychologist, DHQ Faisalabad, Pakistan, Email: faiqacheema0@gmail.com
}

\begin{tabular}{ll} 
ARTICLE INFO \\
\hline Article History: & \\
Received: & October 20, 2021 \\
Revised: & December 10, 2021 \\
Accepted: & December 11, 2021 \\
Available Online: & December 13, 2021
\end{tabular}

\begin{tabular}{l}
\hline Keywords: \\
Depression \\
Anxiety \\
Stress \\
University Students \\
DASS-21 \\
Academic Achievement
\end{tabular}

\begin{abstract}
COVID-19, the worst public health emergency in a decade, has had a profound impact on people's mental health. Universities in Pakistan have reopened, although it is uncertain how to prevent secondary damage to students as a result of the reopening. The purpose of this study was to determine the prevalence of depression, anxiety and stress among students following the reopening of universities after the COVID-19 first wave. Furthermore, gender differences in depression, anxiety, and stress were also investigated, as well as the predictive value of CGPA in depression, anxiety, and stress. The sample was $(\mathrm{N}=360)$ university students. Data was collected from the two cites of Pakistan. The DASS-21 was used to assess levels of depression, anxiety, and stress among students (Lovibond \& Lovibond, 1995). SPSS version 21 was used to analyze the data. Results indicated that the level of psychological distress has increased among university students due to the reopening of universities. Findings revealed significant differences in depression and anxiety levels based on the three academic disciplines. In addition, male students showed significantly higher levels of depression, anxiety and stress than female students and CGPA significantly and negatively predicted depression and stress. Based on the findings of this study, it is suggested that thorough and targeted psychological interventions for students' mental health should be established, particularly in high-risk cities and during the COVID-19 pandemic late phases.
\end{abstract}

(C) 2021 The Authors, Published by iRASD. This is an Open Access Article under the Creative Common Attribution Non-Commercial 4.0

Corresponding Author's Email: sairairfan@uosahiwal.edu.pk

\section{Introduction}

As of February 26th, the Pakistan Ministry of Health reported the country's first case of COVID-19 in Karachi. An upsurge in the affected people in almost all the regions occurred. In this context, competent authorities from Pakistan immediately took steps to prevent the overspread of the pandemic. Eventually, with the global rise in COVID-19 cases, the disease spread to Pakistan. The government announced a lockdown that caused economic, social, emotional, and psychological issues in the whole nation, especially among the students, resulting from noncompliance with the adversity caused to the educational and academic environment (Government of Pakistan, 2021). Many researchers have assessed the effects of the global pandemic on university students worldwide. This study conducted in Pakistan, focused on inciting panic after the first wave of Covid-19, such as the prevalence of depression, anxiety, and stress among university students.

Covid-19 triggered a negative impact on physical health and thrust the social, emotional, and psychological health of the population into the spotlight (Greenberg et al. 2020). In particular, adults have experienced increased levels of depression, anxiety and stress. According to the American Psychological Association (APA, 2021), depression is a 
common mental illness that affects millions of people throughout the world, with certain characteristic features such as persistent sadness and loss of interest in previously pleasurable activities. Anxiety is characterized as a series of emotions and feelings of apprehension, worry, and several physical changes. As defined by the APA (2020), stress is a state of normal reactions toward unwanted or unfavorable events that, if prolonged, can be harmful to the people experiencing these responses.

Depression, anxiety, and stress have been noted to correlate with higher rates of morbidity among students around the globe. Students get stressed out trying to manage academic and social responsibilities. As previous research indicated, the rate of the occurrence of these issues varies globally. Studies on different populations have also revealed a significant association between COVID-19 and psychological distress and other mental health issues (Zaki et al., 2020).

In China, nationwide survey results showed that $35 \%$ of the participants suffered from psychological and mental health problems during COVID-19 (Qiu et al., 2020). Furthermore, due to the COVID-19 pandemic, around $20.4 \%$ of the students experienced minimum to moderate anxiety levels in Malaysia (Kamaludin et al., 2020). A study conducted on recently graduated unemployed youth in Bangladesh has reported depression, anxiety, and stress at $81.1 \%, 61.5 \%$, and $64.8 \%$, respectively. Significant risk factors for depression, anxiety, and stress included gender, age, socioeconomic status, educational background, and high screen time (Mamun et al., 2020). Likewise, a study in Pakistan found psychological issues such as an increase in anxiety and panic, as well as behavioral changes (Balkhi et al., 2020). Another study in Sialkot reported that $75 \%$ of students suffered from depression, $88.4 \%$ from anxiety, and $84.4 \%$ suffered from stress, indicating the commonness of anxiety and stress in students (Asif et al., 2020).

A crisis like COVID-19 can increase various mental disturbances, of which depression, anxiety, and stress are more common among the students. Many studies have been conducted to determine the impact of the coronavirus on the mental health of students. Online surveys on COVID-19 found that female students who had a family member, relative, or friend who was isolated for 14 days and utilized the internet were more likely to experience depression, anxiety and stress. Thus, COVID-19 eventually became a public health emergency and COVID19 's restrictions and prolonged lockdown have a detrimental impact on individuals' wellbeing (Al Omari et al., 2020).

Because of limited information about how COVID-19 affects people's lifestyles, mental health, and physical health, there are no adequate management plans to minimize the negative effects of pandemic. As a result, the purpose of this study was to investigate the prevalence of depression, anxiety and stress among university students following the reopening of universities after the first wave of COVID-19.

\section{Hypotheses}

The following hypotheses have been established based on the literature review:

H1: There would be significant differences in the prevalence rates of depression, anxiety and stress based on discipline after the COVID-19 first wave.

H2: There would be significant differences in depression, anxiety and stress based on gender after the COVID-19 first wave.

H3: There would be a significant relationship between depression, anxiety, stress, CGPA, discipline, and socioeconomic status after the COVID-19 first wave.

H4: Academic Achievement (CGPA) would significantly predict depression, anxiety, and stress after the COVID-19 first wave.

\section{Material and Methods}

A cross-sectional survey design was used in this study. The sample was taken using a purposive sampling technique from different government and private universities in Faisalabad and Sahiwal. University students $(\mathrm{N}=360)$ were invited via WhatsApp and email to participate 
in the research. The sample consisted of participants with an age range of $19-25$ years $(M=$ $1.96, S D=0.8322)$, including $(n=180)$ males and $(n=180)$ females. Using Raosoft's sample size calculator (Raosoft, 2004), sample size was calculated for this study. It was optional for students to participate. Participants were told that their responses would remain private.

\subsection{Instruments}

DASS-21 (Depression Anxiety Stress Scale-21)

With 21 items, DASS-21 (Lovibond \& Lovibond, 1995) is the short form of DASS-42. It is also a self-report scale for measuring negative emotions, such as anxiety, stress, and depression. Clinical and non-clinical purposes can both be addressed by DASS-21, an instrument with high internal consistency. Each scale contains seven items, the responses to which are categorized on a four-point Likert scale, with "0" indicating no reaction and "3" indicating the majority of the time (Lovibond \& Lovibond, 1995). Both scales have strong internal reliability (0.785) according to reliability by McDonald's Omega (Onie et al., 2020). With a Cronbach alpha of .81, the DASS-21 depression scale assesses negative emotions connected to low self-esteem, hopelessness, and low positive sensations and emotions (Lovibond \& Lovibond, 1995). The depression scale was shown to be quite reliable (Coker et al., 2018). The DASS-21 anxiety scale assesses involuntary biological arousals, musculoskeletal symptoms, situational anxiety, and personal anxiety experiences, while the Stress Scale assesses a person's worry, annoyance, and negative emotions (Lovibond \& Lovibond, 1995). The anxiety scale had a Cronbach alpha value of .89 and .78 value for the stress scale, indicating reliability (Coker et al., 2018).

\section{Results}

Table 1: Descriptive Summary of Variables

\begin{tabular}{llllll}
\hline Variables & & \multicolumn{3}{c}{ Range } & \\
\cline { 3 - 4 } & $\mathrm{N}$ & Min & Max & Mean & SD \\
\hline Depression & 360 & 1 & 5 & 3.17 & 1.05 \\
Anxiety & 360 & 1 & 5 & 4.01 & 1.14 \\
Stress & 360 & 1 & 5 & 2.63 & 1.24 \\
Gender & 360 & 1 & 2 & 1.50 & .501 \\
Previous CGPA & 360 & 2 & 4 & 3.17 & .697 \\
\hline
\end{tabular}

Table 1 presents the descriptive statistics of the variables. The mean of all variables was greater than the average.

Table 2: Frequency of Participants in Terms of Depression, Anxiety and Stress

\begin{tabular}{lllllll}
\hline & Depression & \multicolumn{3}{c}{ Anxiety } & \multicolumn{3}{c}{ Stress } \\
\hline Depression & $\begin{array}{c}\text { Frequency } \\
(\mathrm{f})\end{array}$ & $\begin{array}{c}\text { Percentage } \\
(\%)\end{array}$ & $\begin{array}{c}\text { Frequency } \\
(\mathrm{f})\end{array}$ & $\begin{array}{c}\text { Percentage } \\
(\%)\end{array}$ & $\begin{array}{c}\text { Frequency } \\
(\mathrm{f})\end{array}$ & $\begin{array}{c}\text { Percentage } \\
(\%)\end{array}$ \\
\hline Normal & 35 & 9.7 & 22 & 6.1 & 92 & 25.6 \\
Mild & 44 & 12.2 & 15 & 4.2 & 63 & 17.5 \\
Moderate & 132 & 36.7 & 57 & 15.8 & 122 & 33.9 \\
Severe & 124 & 34.4 & 109 & 30.3 & 52 & 14.4 \\
$\begin{array}{l}\text { Extremely } \\
\quad\end{array}$ & 25 & 6.9 & 157 & 43.6 & 31 & 8.6 \\
\hline
\end{tabular}

Table 2 shows that most of the students have moderate to severe level depression, severe or extremely severe anxiety and moderate level of stress.

Table 3 reports the results of the one-way ANOVA analysis. The findings show a considerable difference in depression, anxiety and stress prevalence rates amongst social sciences, BBA, and science. According to the findings, those in the BBA program have higher depression, anxiety, and stress levels than students in other programs. The value of $\eta^{2}$ show very small effect size. The post-hoc comparison revealed considerable dissimilarities of each group with other two groups. 
Table 3: Depression, Anxiety, and Stress in Social Science, Business Administration and Science Faculties: A One-Way Analysis

\begin{tabular}{|c|c|c|c|c|c|c|c|c|c|}
\hline \multirow{2}{*}{$\begin{array}{l}\text { Measure } \\
\text { s }\end{array}$} & \multicolumn{2}{|c|}{ Social sciences } & \multicolumn{2}{|c|}{ BBA } & \multicolumn{2}{|c|}{ Sciences } & \multirow[t]{2}{*}{$F(2,357)$} & \multirow{2}{*}{${ }^{n 2}$ Hoc } & \multirow[t]{2}{*}{ Post- } \\
\hline & $\mathbf{M}$ & SD & $\mathbf{M}$ & SD & $\mathbf{M}$ & SD & & & \\
\hline $\begin{array}{c}\text { Depressio } \\
\mathrm{n}\end{array}$ & 15.78 & 7.16 & 20.6 & 6.34 & 19.07 & 6.97 & $15.345 * * *$ & .079 & $2>3>1$ \\
\hline Anxiety & 16.12 & 8.26 & 21.64 & 5.11 & 19.3 & 6.85 & $19.776 * * *$ & .100 & $2>3>1$ \\
\hline Stress & 16.05 & 7.78 & 21.05 & 4.81 & 19.11 & 6.42 & $18.427 * * *$ & .094 & $2>3>1$ \\
\hline
\end{tabular}

$\mathrm{p}<.001$

Table 4: T-value for Depression, Anxiety, and Stress Based on Gender

Measure Male $\quad$ Female $95 \%$ CI Cohen's d

\begin{tabular}{|c|c|c|c|c|c|c|c|c|c|}
\hline & $M$ & SD & M & SD & $\mathrm{t}$ & $\mathrm{p}$ & LL & UL & \\
\hline Depression & 20.72 & 6.33 & 16.49 & 7.17 & 5.93 & .000 & 2.831 & 5.636 & .62 \\
\hline Anxiety & 20.55 & 6.93 & 17.76 & 7.07 & 3.77 & .000 & 1.338 & 4.243 & .39 \\
\hline Stress & 20.45 & 6.40 & 17.27 & 6.59 & 4.64 & .000 & 1.832 & 4.527 & .48 \\
\hline
\end{tabular}

$* * p<.001$

In table 4 results indicate significant differences in depression level based on gender. Results indicate that male students have higher depression $(M=20.72, S D=6.33)$ than their female counterparts $(M=16.49, S D=7.17), t(358)=5.93, p<.001)$. Male students also have more anxiety $(M=20.55, S D=6.93)$ than female students $(M=22.50, S D=6.93), t$ $(358)=3.77, p<.001)$. Stress is also high in male students $(M=20.45, S D=6.40)$ than females $(M=17.27, S D=6.59), t(358)=4.64, p<.001$. Cohen's $d$ value of depression, anxiety and stress is $.62, .39$ and .48 , which shows small effect size for anxiety and stress and medium for depression.

Table 5: Pearson Correlation Between Depression, Anxiety, Stress, CGPA, Discipline and SES

\begin{tabular}{|c|c|c|c|c|c|c|c|c|c|}
\hline & Variables & $M$ & SD & 1 & 2 & 3 & 4 & 5 & 6 \\
\hline 1 & Depression & 18.61 & 7.08 & 1 & & & & & \\
\hline 2 & Anxiety & 19.16 & 7.13 & $.574 * *$ & 1 & & & & \\
\hline 3 & Stress & 18.8 & 6.68 & $.579 * *$ & $\begin{array}{c}.577 * \\
*\end{array}$ & 1 & & & \\
\hline 4 & CGPA & 3.17 & .697 & $-.162 * *$ & -.051 & -.097* & 1 & & \\
\hline 5 & Discipline & 2.02 & .801 & $.181 * *$ & $\begin{array}{c}.172 * \\
*\end{array}$ & -.178 & .077 & 1 & \\
\hline 6 & SES & 2.01 & .128 & .054 & .053 & .034 & .009 & .053 & 1 \\
\hline
\end{tabular}

Note: $1=$ CGPA (Academic Achievement), $2=$ Discipline of study, $3=$ Socio-economic status, $* p<.05$, $* * p<.01$.

The results in Table 5 show that depression and stress have a significant negative correlation with CGPA. Moreover, depression and anxiety have a significant positive correlation with discipline. Results also specify that depression, anxiety and stress have non-significant correlation with socio-economic status of students. Further, the findings show that anxiety, stress, and depression are all highly linked.

Table 6: Academic achievement (CGPA) As a Predictor of Depression, Anxiety, and Stress

\begin{tabular}{llllllllll}
\hline Variable & Model 1 & \multicolumn{5}{c}{ Model 2 } & \multicolumn{2}{c}{ Model 3 } \\
\hline & B & SE & t & $\boldsymbol{\beta}$ & SE & t & $\boldsymbol{\beta}$ & SE & t \\
\hline CGPA & -.216 & -.143 & $-2.731^{*}$ & -.050 & .087 & $-.574 \mathrm{NS}$ & -.191 & .094 & $-2.034^{*}$ \\
R2 & .020 & & & .001 & & & .011 & & \\
\hline
\end{tabular}

Table 6 shows (see model 1 ) that CGPA significantly predicted the level of depression and explained a significant degree of variance $\left(R^{2}=.020\right)$. In the same vein, CGPA predicted stress levels and described the significant degree of variance in stress level $\left(R^{2}=.011\right)$ (See 
model 3). Moreover, CGPA did not significantly predict the level of anxiety (see model 2) and explained a non-significant degree of variance in anxiety level $\left(R^{2}=.001\right)$.

\section{Discussion}

This study aimed to determine the prevalence of depression, anxiety, and stress following the first wave of the COVID-19 outbreak. Gender differences in depression, anxiety, and stress were also investigated as was the predictive value of CGPA in depression, anxiety, and stress. Due to the reopening of institutes following the COVID-19 first wave, the prevalence rate of depression, anxiety, and stress has increased among university students, with approximately 34.4 percent of 360 participants reporting severe depression, 30.3 percent reporting moderate anxiety, and 43.6 percent reporting extremely severe anxiety. This is supported by research carried out in Islamabad to ascertain that how common depression, anxiety, and stress are (Rizvi et al., 2015). Another study of 500 students at GCWU Sialkot discovered that $75 \%$ of them were depressed, $88.4 \%$ were anxious, and 84.4 percent were stressed (Asif et al., 2020). According to the findings, 40.9 percent of 66 students had depression (9.09 percent had mild depression, 16.67 percent had moderate depression, 13.64 percent had severe depression, and 1.52 percent had extremely severe depression). Anxiety was present in 74.2 percent of the subjects $(13.64$ percent $=$ mild; $27.4 \%=$ severe). Participants in another study reported being stressed $50 \%$ of the time (Rizvi et al., 2015). Similarly, according to research conducted on Spanish students during the lockdown, 34.19 percent of pupils had extremely severe depression, severe form of anxiety was reported by 21.34 percent students and 28.14 percent experienced moderate levels of stress (OdriozolaGonzález et al., 2020). Cao et al. (2020) reported that 2.7 percent of Chinese school pupils felt moderate anxiety during the COVID-19 crisis, while 0.9 percent reported severe anxiety.

Findings of this study showed significant differences in depression, anxiety and stress prevalence rates among students in the Social Sciences, Business Administration, and Science faculties. This finding is supported by another study which found that medical students have high psychological distress levels, with significant changes between semesters. The mental health of medical students seems to be influenced by gender and religion (Moutinho et al., 2017). Similarly, another study conducted on Spanish university students revealed that Faculty of Arts and Social Science students reported higher levels of psychological distress than students in other faculties (Odriozola-González et al., 2020). Similarly, in another study psychology students had lower depression and anxiety ratings than science students (Debowska et al., 2020).

Findings of the current study also demonstrated substantial gender differences in depression, anxiety, and stress prevalence rates, implying that men had higher depression, anxiety, and stress levels than females. It is in line with a previous study that showed considerable gender differences in depression levels, with male participants displaying higher levels of depression than females (Salk et al., 2017). Contrary to the above findings, a study conducted in China reported higher levels of anxiety and stress in females than in males, and overall depression and anxiety were also higher among the Chinese population due to COVID19 (Hou et al., 2020).

Correlation analysis showed that stress and depression have a significant negative association with CGPA. According to the findings of this study, depression and anxiety also have a strong positive relationship with discipline. Moreover, depression, anxiety, and stress have a non-significant relationship with socioeconomic status, Furthermore, the findings showed a considerable positive association between depression, anxiety, and stress. These findings are in line with previous studies. Lee, Jeong, Kim (2021) reported that mental health problems were more common among female, rural, low-income, and academically underachieving pupils. Moreover, Xu and Wei (2013) revealed that depression and anxiety had a substantial positive relationship with each other.

The findings of the current study showed that CGPA is a strong predictor of depression and stress among university students. Academic achievement has been linked to stress levels in students (Siraj et al., 2014; Kumari \& Gartia, 2012), and CGPA is a predictor of stress (Ranasinghe et al., 2017), which confirms the findings of this study. 


\subsection{Limitations and suggestions}

Although this study provides valuable information, it has certain limitations. Firstly, the generalizability of the sample is limited because the data was collected only from two cities. Secondly, the subjective nature of participants' responses to depression, anxiety, and stress would not be adequate to affirm that the symptoms are only due to COVID-19 effects. Thirdly, this is correlational research that limits the predictability that only COVID-19 causes psychological issues among university students. Detailed analysis and studies are required to confirm the actual effects of COVID-19 on student behavior and functioning. Also important would be the collection of data from a broader sample from different major cities in Pakistan.

\section{Conclusion}

This was one of the few investigations during the COVID-19 pandemic that looked into the prevalence of depression anxiety and stress. The results and recommendations of this study should be considered by healthcare practitioners, legislators, and decision-makers when developing new crisis programs to overcome the psychological needs of university students and to control and avert the onset of mental illness in the future. To achieve this, students require continuous support, monitoring, counseling, and psychological management training. To gain a better understanding of depression, anxiety, and stress among university students, the current study should be repeated with additional variables.

\section{References}

Al Omari, O., Al Sabei, S., Al Rawajfah, O., Abu Sharour, L., Aljohani, K., Alomari, K., Shkman, L., Al Dameery,K., Saifan, A., Al Zubidi, B., Anwar, S., \& Alhalaiqa, F. (2020). Prevalence and predictors of depression, anxiety, and stress among youth at the time of COVID-19: An online cross-sectional multicountry study. Depression Research and Treatment. https://doi.org/10.1155/2020/8887727

American Psychological Association. (2021). Psychology Topics: Anxiety. http://www.apa.org/topics/anxiety

American Psychological Association. (2020, April 14). Coping with COVID-19-related stress as a student. http://www.apa.org/topics/covid-19/student-stress

Asif, S., Mudassar, A., Shahzad, T. Z., Raouf, M., \& Pervaiz, T. (2020). Frequency of depression, anxiety, and stress among university students. Pakistan Journal of Medical Sciences, 36(5), 971-976. https://doi.org/10.12669/pjms.36.5.1873

Balkhi, F., Nasir, A., Zehra, A., \& Riaz, R. (2020). Psychological and behavioral response to the coronavirus (COVID-19) pandemic. Cureus. https://doi.org/10.7759/cureus.7923

Cao, W., Fang, Z., Hou, G., Han, M., Xu, X., Dong, J., \& Zheng, J. (2020). The psychological impact of the COVID-19 epidemic on college students in China. Psychiatry research, 287, 112934.

Coker, A. O., Coker, O. O., \& Sanni, D. (2018). Psychometric properties of the 21-item depression anxiety stress scale (DASS-21). African Research Review, 12(2), 135-142.

Debowska, A., Horeczy, B., Boduszek, D., \& Dolinski, D. (2020). A repeated cross-sectional survey assessing university students' stress, depression, anxiety, and suicidality in the early stages of the COVID-19 pandemic in Poland. Psychological Medicine, 1-4. https://doi.org/10.1017/s003329172000392x

Greenberg, N., Docherty, M., Gnanapragasam, S., \& Wessely, S. (2020). Managing mental health challenges faced by healthcare workers during COVID-19 pandemic. BMJ, m1211. https://doi.org/10.1136/bmj.m1211

Government of Pakistan. (2021). Know about COVID-19. COVID-19 Health Advisory Platform by Ministry of National Health Services Regulations and Coordination. https://covid.gov.pk/.

Hou, F., Bi, F., Jiao, R., Luo, D., \& Song, K. (2020). Gender differences of depression and anxiety among social media users during the COVID-19 outbreak in China: A crosssectional study. BMC public health, 20(1), 1-11.

Kamaludin, K, Chinna, K., Sundarasen, S., Khoshaim, H. B., Nurunnabi, M., Baloch, G.M., Sukayt, A., Hossain, S. F. A. (2020). Coping with COVID-19 and movement control order (MCO): Experiences of university students in Malaysia, Heliyon, 6 (11), e05339, https://doi.org/10.1016/j.heliyon.2020.e05339.

Kumari, R., \& Gartia, R. (2012). Relationship between stress and academic achievement of senior secondary school students. Asian Journal of Multidimensional Research $(A J M R), 1(3), 152-160$. 
Lee, J., Jeong, H. J., Kim, S. (2021). Stress, anxiety and depression among undergraduate students during the COVID-19 and their use of mental health services, Innov High Educ, 1-20. https://doi.org/10.1007\%2Fs10755-021-09552-y

Lovibond, P., \& Lovibond, S. (1995). The structure of negative emotional states: Comparison of the depression anxiety stress scales (DASS) with the Beck Depression and Anxiety Inventories. Behaviour Research and Therapy, 33(3), 335-343. https://doi.org/10.1016/0005-7967(94)00075-u

Mamun, M. A., Akter, S., Hossain, I., Hasan Faisal, M. T., Rahman, M. A., Arefin, A., Khan, I., Hossain, L., Haque, M. A., Hossain, S., Hossain, M., Sikder, M. T., Kircaburun, K., \& Griffiths, M. D. (2020). Financial threat, hardship and distress predict depression, anxiety and stress among the unemployed youths: A Bangladeshi multi-city study. Journal of Affective Disorders, 276, 1149-1158. https://doi.org/10.1016/j.jad.2020.06.075

Moutinho, I. L. D., Maddalena, N. D. C. P., Roland, R. K., Lucchetti, A. L. G., Tibiriçá, S. H. C., Ezequiel, O. D. S., \& Lucchetti, G. (2017). Depression, stress and anxiety in medical students: A cross-sectional comparison between students from different semesters. Revista da Associação Médica Brasileira, 63, 21-28.

Odriozola-González, P., Planchuelo-Gómez, Á., Irurtia, M. J., \& De Luis-García, R. (2020). Psychological effects of the COVID-19 outbreak and lockdown among students and workers of a Spanish university. Psychiatry Research, 290, 113108. https://doi.org/10.1016/j.psychres.2020.113108

Onie, S., Kirana, A. C., Mustika, N. P., Adesla, V., \& Ibrahim, R. (2020). Assessing the predictive validity and reliability of the DASS-21, PHQ-9 and GAD-7 in an Indonesian Sample. https://doi.org/10.31234/osf.io/eqcm9

Qiu J, Shen B, Zhao M, Wang Z, Xie B, Xu Y. (2020). A nationwide survey of psychological distress among Chinese people in the COVID-19 epidemic: Implications and policy recommendations. Gen Psychiatry, 33. https://doi.org/10.1136/gpsych-2020-100213

Ranasinghe, P., Wathurapatha, W. S., Mathangasinghe, Y., \& Ponnamperuma, G. (2017). Emotional intelligence, perceived stress and academic performance of Sri Lankan medical undergraduates. BMC Medical Education, 17(1). https://doi.org/10.1186/s12909-017-0884-5

Raosoft, I. (2004). Raosoft Sample Size Calculator. http://www.raosoft.com/samplesize.html

Rizvi, F., Qureshi, A., Rajput, A. M., \& Afzal, M. (2015). Prevalence of depression, anxiety and stress (by DASS scoring system) among medical students in Islamabad, Pakistan. Journal of Advances in Medicine and Medical Research, 69-75.

Salk, R. H., Hyde, J. S., \& Abramson, L. Y. (2017). Gender differences in depression in representative national samples: Meta-analyses of diagnoses and symptoms. Psychological bulletin, 143(8), 783.

Siraj, H. H., Salam, A., Roslan, R., Hasan, N. A., Jin, T. H., \& Othman, M. N. (2014). Stress and its association with the academic performance of undergraduate fourth year medical students at Universiti Kebangsaan Malaysia. IIUM Medical Journal Malaysia, 13(1).

Xu, J., Wei, Y. (2013). Social support as a moderator of the relationship between anxiety and depression: An empirical study with adult survivors of Wenchuan earthquake. PLoS One, 8(10), e79045. https://doi.org/10.1371/journal.pone.0079045

Zaki, W.N., Sidiq, M., Qasim, M., Aranas, B., Hakamy, A., Ruwais, N. A., Alanezi, H., Al Saudi' D. A., Alshahrani, R. B. S., Al-Thomali, A. B A., Manzar, M. D., BaHammam, A. S., Al-Kaabba, A. F., Pandi-Perumal' S. R. (2020). Stress and psychological consequences of COVID-19 on health-care workers.J Nat Sci Med. 3(4), 299-307. https://doi.org/ 10.4103/JNSM.JNSM_86_20 